\section{Preparing physicians for the real world}

$\mathrm{I}^{\mathrm{r}}$ ead with interest the article by Christopher Parshuram and associates $^{1}$ about fellowship training. My question is this: How do you prepare a 60 -year-old physician to work 30 hours continuously with no sleep, in a job where he or she is the most responsible referral physician for a population of 130 000, without doing something similar in the residency program? That is the reality of life for older physicians in the area where I work.

John C. Acres

Cape Breton Regional Hospital

Sydney, NS

\section{Reference}

1. Parshuram CS, Dhanani S, Kirsh JA, Cox PN. Fellowship training, workload, fatigue and physical stress: a prospective observational study. CMA7 2004;170(6):965-70.

DOI:10.1503/cmaj.1040528

\section{[Dr. Parshuram responds:]}

$\mathrm{T}$ he current situation for trainees reflects tensions among needs for timely and adequate exposure to clinical experience, opportunities to attend and benefit from - formal education sessions and provision of 24-hour coverage, as well as the priorities of health care budgets. Self-management of fatigue may be an important but unstated aspect of physician training. However, increasing sleep deprivation is associated with deterioration in performance for all human beings ${ }^{1}$ and the occurrence of errors ${ }^{2}$ and adverse events ${ }^{3}$ in health care. Discontinuity of care also increases adverse events. ${ }^{4}$

But is the reality of professional life for physicians, as described by John Acres, a desirable reality that we should be striving to sustain? In our study the average departure time of staff intensivists was after $9 \mathrm{pm}$, they were away from the unit for an average of 9.5 hours per day, they returned overnight every fifth on-call day, and they had contact with on-call, in-house physicians once or twice each night. With continuous on-call periods of 3 to 4 days, the potential for sleep deprivation and fatigue among these staff physicians should not be discounted, but any fatigue-related effect on patients was probably counterbalanced by the benefits of continuity. The "best" practice pattern has yet to be defined ${ }^{6}$ but it requires balancing a variety of factors related to continuity of care, fatigue and physician well-being.

In short, the final answers to the broader question raised by Acres are not yet in. Diverse and potentially competing interests will make resolution of this problem particularly challenging. Given the magnitude of the changes that will be required, careful evaluation is warranted before expensive but imperfect solutions are put into place.

\section{Christopher S. Parshuram}

Department of Critical Care Medicine

Hospital for Sick Children

Toronto, Ont.

\section{References}

1. Dawson D, Reid K. Fatigue, alcohol and performance impairment [letter]. Nature 1997;388:235.

2. Barth B, Hendey GW, Soliz T. Errors in postcall medication orders. Acad Emerg Med 2001;8: 468-9.

3. Aya AG, Mangin R, Robert C, Ferrer JM, Eledjam JJ. Increased risk of unintentional dural puncture in night-time obstetric epidural anesthesia. Can 7 Anaesth 1999;46:665-9.

4. Petersen LA, Brennan TA, O'Neil AC, Cook EF, Lee TH. Does housestaff discontinuity of care increase the risk for preventable adverse events? Ann Intern Med 1994;121:866-72.

5. Parshuram CS, Dhanani S, Kirsh JA, Cox PN. Fellowship training, workload, fatigue and physical stress: a prospective observational study. CMA7 2004;170(6):965-70.

6. Gaba DM, Howard SK. Patient safety: fatigue among clinicians and the safety of patients. $N$ Engl f Med 2002;347:1249-55.

DOI:10.1503/cmaj.1040887

\section{[Dr. Howard responds:]}

T ong hours of work in opposition to our circadian clock lead inevitably to a physiologic process that manifests as fatigue. Sleep deprivation and fatigue in turn lead to predictably negative effects on performance and mood, combining to produce situations where health care providers are at risk of harming patients.

The issues of how and when we work cannot be addressed by a single schedule, and there is no magic bullet. The type of professional life described by John Acres is all too familiar, the output of a flawed system that needs to be changed. ${ }^{2}$ Limitation of work hours is only one of many changes that could improve the health care system..$^{1,3}$ No training system can alter basic human physiology, so making trainees work unreasonable schedules does little but perpetuate the problem.

Health care is a hazardous industry where we do risky things to patients. Practitioners owe it to their patients to be optimally alert and able to perform. No health care professional would find it acceptable to arrive at work impaired by ethanol, yet many of us similarly impaired by chronic loss of sleep continue to care for patients. ${ }^{5-7}$ Work schedules such as Acres describes must be challenged so that a new reality can be developed to improve both patient care and physicians' health.

\section{Steven K. Howard}

VA Palo Alto Health Care System

Stanford University School of Medicine Palo Alto, Calif.

\section{References}

1. Howard SK, Rosekind MR, Katz JD, Berry AJ. Fatigue in anesthesia: implications and strategies for patient and provider safety. Anesthesiology 2002;97:1281-94.

2. Gaba DM, Howard SK. Patient safety: fatigue among clinicians and the safety of patients. $N$ Engl 7 Med 2002;347:1249-55.

3. Howard SK, Gaba DM. Trainee fatigue: Are new limits on work hours enough? CMAJ 2004; 170(6):975-6.

4. Gaba DM. Structural and organizational issues in patient safety: a comparison of health care to other high-hazard industries. Calif Manage Rev 2000;43:83-102.

5. Dawson D, Reid K. Fatigue, alcohol and performance impairment [letter]. Nature 1997;388:235.

6. Powell NB, Riley RW, Schechtman KB, Blumen MB, Dinges DF, Guilleminault C. A comparative model: reaction time performance in sleep- 